\title{
Underweight and associated factors among lactating women in Uganda: evidence from the Uganda demographic health survey 2016.
}

quraish sserwanja ( $\nabla$ qura661@gmail.com )

Doctors with Africa https://orcid.org/0000-0003-0576-4627

David Mukunya

University of Bergen

Linet M. Mutisya

Uppsala University

Milton Musaba

Makerere University College of Health Sciences

Mathew Kagwisagye

Makerere University

Ivan Arinda Kato

Makerere University College of Health Sciences

Robert Tuke

Michigan State University

Theogene Habumugisha

University of Bergen

Joseph Kawuki

Southeast University

Research article

Keywords: Underweight, Prevalence, Lactating-women, Uganda

Posted Date: June 8th, 2020

DOI: https://doi.org/10.21203/rs.3.rs-32018/v1

License: (1) (i) This work is licensed under a Creative Commons Attribution 4.0 International License.

Read Full License

Version of Record: A version of this preprint was published at Health Science Reports on August 13th, 2021. See the published version at https://doi.org/10.1002/hsr2.356. 


\section{Abstract}

\section{Background}

Lactating mothers are at increased risk of underweight due to physiological changes that lead to disproportionately higher energy and nutrient requirements than non-pregnant and non-lactating women. Maternal underweight has been shown to negatively affect the secretion of nutrients in breast milk leading to increased risk of child morbidity and mortality. We aimed to determine the prevalence and factors associated with underweight among lactating women in Uganda.

\section{Methods}

We used the Uganda Demographic and Health Survey (UDHS) 2016 data of 1,356 women aged 20 to 49 years. Multistage stratified sampling was used to select study participants and data were collected using validated questionnaires. We used multivariable logistic regression to determine factors associated with underweight among 20 to 49-year-old lactating women in Uganda.

\section{Results}

The prevalence of underweight was $8.2 \%$ (111/1356) (95\% Cl: 7.0-10.0). Women who were working were more likely to be underweight compared to those who were not working ( $\mathrm{AOR}=0.51 ; 95 \% \mathrm{Cl}$ : $0.28-0.96)$. Women in the Northern region were more likely to be underweight compared to women in the Western $(A O R=0.14 ; 95 \% \mathrm{Cl}: 0.06-0.29)$, Eastern (AOR $=0.34 ; 95 \% \mathrm{Cl}: 0.18-0.64)$ and Central $(\mathrm{AOR}=0.24 ; 95 \% \mathrm{Cl}$ : $0.10-0.57)$ regions. Women who had no education ( $\mathrm{AOR}=9.27 ; 95 \% \mathrm{Cl}: 1.61-53.52)$ or, primary education ( $A O R=6.00 ; 95 \% \mathrm{Cl}: 1.13-31.98)$ were more likely to be underweight compared to those who had higher (post-secondary) education level.

\section{Conclusion}

Our study established that the factors associated with underweight among Ugandan lactating women were level of education, working status and region. Based on the findings of this and other studies, it is important for the government to design targeted underweight reduction programs with special emphasis on working, women from the Northern region and those whose highest level of education is primary.

\section{Introduction}

Maternal and child nutritional status is a good indicator of the overall wellbeing of a society (1). Globally, $10 \%$ of women aged 20 to 49 are underweight (2) with the greatest burden in low- income countries (3). Underweight is an indicator of undernutrition, an adult is considered underweight when their body mass index is below $18.5 \mathrm{~kg} / \mathrm{m}^{2}$ (4). Lactation and pregnancy are particularly demanding periods for women because of the increased demand for calories and nutrients, often at the expense of the woman's health if the oral intake is not commensurate $(1,5)$. 
The World Health Organization (WHO) recommends up to two years of breastfeeding with six months of exclusive breastfeeding (6), yet breast milk production largely depends on the nutritional status of the mother hence it is crucial to ensure adequate nutrition among lactating women (6). Additionally, the WHO recommends a birth to pregnancy interval of at least 24 months in order for the physiological changes of pregnancy to be reversed to allow full recovery from the preceding pregnancy (7).

With maternal underweight, the quality and quantity of nutrients in breast milk is negatively affected leading to increased risk of child morbidity, mortality and a long term impact on the child's health $(8,9)$. Under-nutrition in lactate women induces nutrition related metabolic disturbances in early infancy and irreversible physiologic alterations in infants (10). The nutritional demand is high for lactating women (11) yet women in low-income countries are at a high risk of not meeting their nutrient requirements (12) because of inadequate food supply due to financial constraints $(13,14)$.

Women in Uganda are economically disadvantaged as they have less control of resources like land, much involvement in unpaid care work, work longer hours than men and less access to credit services (15). The majority of the reported studies in Uganda have mainly focused on prenatal and under-five nutrition overlooking another high risk group of pregnant and lactating women despite studies in developing countries showing a high prevalence of underweight among lactating women. This knowledge gap impedes designing of national nutrition policies for pregnant and lactating women. Hence this study aimed to determine the prevalence and associated factors of underweight among lactating women in Uganda.

\section{Methods}

\section{Study Data}

We used secondary data of the 2016 Uganda demographic health survey collected from 20th June 2016 to 16th December 2016 (16) It was a nationally representative survey carried out by the Uganda Bureau of Statistics as part of the international MEASURE Demographic Health Surveys (DHS) with the support of ICF International and United States Agency for International Development (USAID) (16). UDHS is a periodical survey conducted every five years. UDHS 2016 had four different questionnaires (16). Household questionnaire collected data on household environment, assets and members while women's questionnaire collected data about women's background characteristics, reproductive health, domestic violence and nutrition (16). The men's questionnaire collected men's health indicators' data while the biomarker questionnaire collected data on anthropometry and blood tests (16). Regarding anthropometry, weight was recorded in kilograms to the nearest one decimal point and was measured using an electronic scale ( SECA 878) while height was recorded in centimeters to one decimal point (16).

\section{Study Setting}


As of July 2018 , Uganda had a population of $40,853,749$ million people with $23.8 \%$ of the population residing in urban areas and the country has a total area of 241,551 square kilometres $(17,18)$. Uganda's health system has six levels ranging from the highest level of national referral hospitals to the lowest level at the community level (19). Agriculture contributes about $24 \%$ of gross domestic product (GDP), providing half of the export earnings and is the primary source of income for the majority of Ugandans (18).

\section{Study Sampling And Participants}

Samples were collected using stratified two-stage cluster sampling design with census enumeration areas as the primary sampling units (16). The first stage of sampling involved selecting 697 enumeration areas (EAs), including 162 urban and 535 rural enumeration areas selected from the list of the 2014 population and housing census sample frame (16). One enumeration area in Acholi region was excluded due to land disputes hence ending up with 696 EAs. Enumeration areas with over 300 households were segmented and only one segment selected with probability proportional to the segment size as this helped minimize the burden of the household listing (16). The enumeration areas that were involved in the survey were chosen independently from each stratum with probability proportional to size. The second stage of sampling involved the selection of households through equal probability systematic sampling. A list containing all households and maps in the selected enumeration area was made available, and households that were in institutional living arrangements were excluded (16). Women aged 15 to 49 years who were either the permanent residents or slept in the selected household the night before were eligible for inclusion in Uganda's demographic health survey 2016 (16). During the survey, anthropometric measurements were done for women who were not pregnant or had no birth two months before the survey (16). Our secondary analysis only considered 20 to 49 -year-old lactating women and excluded 15 to 19-year-old women (adolescents) because the recommended anthropometric indicators for assessing underweight for those above 20 are different from those of adolescents. Of the 18,506 women who consented and filled in the questionnaires, 14,242 were aged 20 to 49 years and of these, 4731 were eligible for anthropometry, 4640 had their anthropometry done and 1356 were breastfeeding (16). To maintain the representativeness of the sample and possible differences in response rates across regions, sampling weights were used.

\section{Outcome Variables}

In this study, underweight was the outcome variable and was defined as body mass index (BMI) less than (<) $18.5 \mathrm{~kg} / \mathrm{m}^{2}(4)$.

\section{Explanatory Variables}


This study included determinants of underweight based on evidence from available literature and data. These factors were divided into the individual level (age, marital status, working status and education level), household level (wealth index, household size and sex of household head) and community level (region and residence) characteristics. The "Wealth index" is a measure of relative household economic status and was calculated by DHS from information on household asset ownership using Principal Component Analysis $(16,20)$. Different household assets were used to calculate separate wealth indices for rural and urban areas, combined into a national wealth index and these quintiles are; the poorest, the poorer, the middle, the richer and the richest quintiles $(16,20)$. Place of Residence was aggregated as urban and rural. The "region" was categorized into four; Northern (Teso, Karamoja, Lango, Acholi, West Nile), Central (Kampala, Central 1 and Central 2), Eastern (Busoga, Bugishu and Bukedi) and Western (Tooro, Ankole, Bunyoro and Kigezi) (21). Level of Education was categorized into: no education, primary education, secondary and higher education. Age was categorized into 20-29, 30-39 and 40-49. Household Size was categorized as less than six members and six and above members. Sex of Household Head was categorized as male or female. Working status was categorized as: not working and working. Marital Status was categorized into married, and this included those in formal and informal unions and not married. Antenatal care (ANC) utilisation frequency was divided into less than four visits and four and above visits.

\section{Statistical Analysis}

We used the SPSS analytic software version 25.0 Complex Samples package for this analysis. Use of the complex samples package accounted for the complex survey sampling while the use of sample weighted data accounted for the unequal probability sampling in different strata. Frequency tables and proportions were used to describe categorical variables while means and standard deviations for continuous variables. Initially, each exposure was assessed separately for its association with the outcome variable using bivariable logistic regression, and we presented crude odds ratio (COR), 95\% confidence interval (Cl) and p-values. Independent variables found significant at p-value less than $0.2(11,22)$ were included in the multivariable model. We used variance inflation factor to rule out multi-co-linearity and Hosmer and Lemeshow goodness of fit test for the adequacy of the models (12).

In the multivariable analysis, we constructed two models based on the categorization of the independent variables into "individual" and "household and community level" factors. We first performed a logistic regression model which included only individual characteristics (level of education and working status) that were found significant at the binary logistic regression level. Then after, we constructed a final model which included individual characteristics adjusted for household and community characteristics (wealth index, residence and region). Adjusted odds ratios (AOR), 95\% Confidence Intervals (CI) and p-values were calculated with a statistical significance level set at $p$-value $<0.05$. Sensitivity analysis was done with only women who were underweight and had normal BMl after excluding those with BMI above 25 .

\section{Results}


A total of 1,356 lactating women were included in this study (Table 1). Over half of the women were aged between 20 and 29 years (61.5\%), resided in rural areas (80.5\%), were currently working $(82.7 \%)$ and married (88.1\%). In addition, more women lived in households with more than six members (54.5\%), had primary education as the highest level (59.5\%) and resided in male-headed households (74.7\%).

Regarding geographical location, Northern region had the highest proportion of respondents $(30.6 \%)$ while Eastern had the lowest (20.0\%). Study participants are almost equally distributed in each wealth quintile. The mean age, weight, height, household size and BMI were $28.44 \pm 6.21,57.83 \pm 10.66,159.09 \pm$ $6.39,6.23 \pm 2.72$, and $22.83 \pm 3.89$ respectively.

The prevalence of underweight was $8.2 \%$ (95\% Cl: 7.0-10.0), and of these, $75.9 \%$ were mildly underweight, $20.5 \%$ moderately underweight, and $3.6 \%$ severely underweight. 
Table 1

Background characteristics of lactating Ugandan women aged 20-49 years as per the 2016 UDHS.

\begin{tabular}{|lll|}
\hline Characteristics & $\mathbf{N}=1356$ & $\%$ \\
\hline Age & & \\
\hline 20 to 29 & 834 & 61.5 \\
\hline 30 to 39 & 441 & 32.5 \\
\hline 40 to 49 & 81 & 06.0 \\
\hline Residence & & \\
\hline Rural & 1092 & 80.5 \\
\hline Urban & 264 & 19.5 \\
\hline Region & & 26.6 \\
\hline Western & 361 & 20.0 \\
\hline Eastern & 272 & 22.7 \\
\hline Central & 308 & 30.6 \\
\hline Northern & 415 & \\
\hline Sex household head & & 25.3 \\
\hline Female & 11.9 \\
\hline Male & 343 & 74.7 \\
\hline Household Size & 1013 & \\
\hline 6 and Above & & 54.5 \\
\hline Less than 6 & 738.7 \\
\hline Working status & & \\
\hline Not working & & \\
\hline Working & & \\
\hline Marital status & & \\
\hline Married & & \\
\hline Not married & & \\
\hline Education Level & & \\
\hline
\end{tabular}

${ }^{a}=$ Working status had 1 missing value, ${ }^{b}=$ ANC frequency had 2 missing values 


\begin{tabular}{|lll|}
\hline Characteristics & $\mathbf{N}=\mathbf{1 3 5 6}$ & $\%$ \\
\hline No Education & 166 & 12.2 \\
\hline Primary Education & 807 & 59.5 \\
\hline Secondary Education & 280 & 20.7 \\
\hline Higher & 103 & 07.7 \\
\hline Wealth Index & & \\
\hline Poorest & 330 & 24.3 \\
\hline Poorer & 291 & 21.4 \\
\hline Middle & 268 & 19.7 \\
\hline Richer & 227 & 16.8 \\
\hline Richest & 241 & 17.7 \\
\hline Underweight & & 08.2 \\
\hline Yes & 111 & 91.8 \\
\hline No & 1245 & \\
\hline ANC Frequency & & 40.4 \\
\hline Less than 4 visits & 547 & 59.6 \\
\hline 4 visits and above & 806 & \\
\hline a =Working status had 1 missing value, ${ }^{\mathrm{b}}=$ ANC frequency had 2 missing values \\
\hline
\end{tabular}

\section{Factors associated with Underweight.}

Table 2 shows the findings of bivariable analysis. After adjusting for individual characteristics, both working status and education level were found to be associated with underweight. In the final logistic regression model, factors associated with underweight were: region, education level and working status as shown in Table 3. Women who had no education (AOR $=9.27 ; 95 \% \mathrm{Cl}: 1.61-53.52)$, primary education $(A O R=6.00 ; 95 \% \mathrm{Cl}: 1.13-31.98)$ were 9.27 and 6 times respectively more likely to be underweight compared to those who had higher (post-secondary) education level.

Women who were not working were $49 \%$ less likely to be underweight compared to those working (AOR = $0.51 ; 95 \% \mathrm{Cl}: 0.28-0.96)$. Women in the Western (AOR = 0.14; 95\% Cl: 0.06-0.29), Eastern (AOR = 0.34; $95 \% \mathrm{Cl}: 0.18-0.64)$ and Central $(\mathrm{AOR}=0.24 ; 95 \% \mathrm{Cl}: 0.10-0.57)$ regions were $86 \%, 66 \%$ and $76 \%$ less likely respectively to be underweight compared to those in the Northern region. 
Table 2

Bivariable analysis of determinants of underweight among lactating Ugandan women aged $20-49$ years

\begin{tabular}{|c|c|c|c|}
\hline Characteristics & $\begin{array}{l}\text { Underweight } \\
n=111\end{array}$ & $\begin{array}{l}\text { Not underweight } \\
n=1245\end{array}$ & P-Value \\
\hline Household Head & & & 0.728 \\
\hline Female & $30(26.7)$ & $313(25.2)$ & \\
\hline Male & 81(73.3) & $932(74.8)$ & \\
\hline Wealth Index & & & $<0.001 *$ \\
\hline Poorest & $50(45.0)$ & $280(22.5)$ & \\
\hline Poorer & $26(23.7)$ & 265 (21.2) & \\
\hline Middle & 15 (13.3) & $253(20.3)$ & \\
\hline Richer & 15 (13.3) & $212(17.1)$ & \\
\hline Richest & $5(04.7)$ & 235 (18.9) & \\
\hline Working Status ${ }^{a}$ & & & $0.003 *$ \\
\hline Not Working & $9(8.1)$ & $224(18.0)$ & \\
\hline Working & 102 (91.9) & 1020 (82.0) & \\
\hline Education Level & & & $<0.001 *$ \\
\hline No Education & $25(22.0)$ & $141(11.3)$ & \\
\hline Primary & $72(64.9)$ & 735 (59.0) & \\
\hline Secondary & $13(12.0)$ & $267(21.4)$ & \\
\hline Higher & $1(1.1)$ & $102(8.2)$ & \\
\hline Region & & & $<0.001 *$ \\
\hline Western & $9(8.0)$ & 352 (28.3) & \\
\hline Eastern & $16(14.7)$ & 255 (20.5) & \\
\hline Central & $11(9.8)$ & 297 (23.9) & \\
\hline Northern & $75(67.6)$ & $341(27.4)$ & \\
\hline Marital Status & & & 0.501 \\
\hline Married & $100(90.1)$ & 1095 (87.9) & \\
\hline
\end{tabular}

$\mathrm{a}=$ Working status had 1 missing value, *= Significant at $p$-value $<0.20$ 


\begin{tabular}{|c|c|c|c|}
\hline Characteristics & $\begin{array}{l}\text { Underweight } \\
\mathrm{n}=111\end{array}$ & $\begin{array}{l}\text { Not underweight } \\
n=1245\end{array}$ & P-Value \\
\hline Not Married & $11(9.9)$ & $150(12.1)$ & \\
\hline Age & & & 0.978 \\
\hline 20 to 29 & $68(61.4)$ & $765(61.5)$ & \\
\hline 30 to 39 & $37(33.0)$ & $405(32.5)$ & \\
\hline 40 to 49 & $6(5.6)$ & $75(6.0)$ & \\
\hline Residence & & & $0.090 *$ \\
\hline Rural & $97(87.5)$ & 995 (79.9) & \\
\hline Urban & $14(12.5)$ & $250(20.1)$ & \\
\hline Household Size & & & 0.570 \\
\hline Six and Above & $58(51.8)$ & $681(54.7)$ & \\
\hline Less than 6 & $53(48.2)$ & $564(45.3)$ & \\
\hline ANC Frequency & & & 0.528 \\
\hline Less than 4 visits & $99(43.2)$ & $499(40.2)$ & \\
\hline 4 visits and above & $63(56.8)$ & $743(59.8)$ & \\
\hline
\end{tabular}


Table 3

Multi-variable analysis of determinants of underweight among lactating Ugandan women aged 2049 years.

\begin{tabular}{|c|c|c|c|}
\hline \multirow[t]{2}{*}{ Characteristics } & $\begin{array}{l}\text { Crude model }(n= \\
1356)\end{array}$ & $\begin{array}{l}\text { Final Model }(n= \\
1356)\end{array}$ & $\begin{array}{l}\text { Sensitivity Model }(n= \\
\text { 1067) }\end{array}$ \\
\hline & OR $(95 \% \mathrm{Cl})$ & AOR $(95 \% \mathrm{Cl})$ & AOR $(95 \% \mathrm{Cl})$ \\
\hline \multicolumn{4}{|l|}{ Age } \\
\hline 40 to 49 & 1 & & \\
\hline 30 to 39 & $1.08(0.49-2.38)$ & & \\
\hline 20 to 29 & $1.10(0.47-2.56)$ & & \\
\hline \multicolumn{4}{|l|}{ Education Level } \\
\hline Higher & 1 & 1 & 1 \\
\hline Secondary & $4.21(0.86-20.59)$ & $4.29(0.70-26.52)$ & $3.79(0.57-25.35)$ \\
\hline Primary & $8.27(1.85-36.88)$ & $6.00(1.13-31.98)$ & $5.84(0.97-35.07)$ \\
\hline No Education & $14.59(3.11-68.58)$ & $9.27(1.61-53.52)$ & $9.06(1.41-58.29)$ \\
\hline \multicolumn{4}{|l|}{ Marital Status } \\
\hline Not married & 1 & & \\
\hline Married & $1.25(0.65-2.41)$ & & \\
\hline \multicolumn{4}{|l|}{ Working Status } \\
\hline Working & 1 & 1 & 1 \\
\hline Not working & $0.40(0.22-0.74)$ & $0.51(0.28-0.96)$ & $0.52(0.28-0.98)$ \\
\hline \multicolumn{4}{|l|}{ Region } \\
\hline Northern & 1 & 1 & 1 \\
\hline Western & $0.12(0.06-0.24)$ & $0.30(0.20-0.44)$ & $0.35(0.24-0.51)$ \\
\hline Eastern & $0.29(0.16-0.53)$ & $0.42(0.28-0.63)$ & $0.44(0.29-0.67)$ \\
\hline Central & $0.17(0.07-0.39)$ & $0.42(0.25-0.72)$ & $0.51(0.30-0.89)$ \\
\hline \multicolumn{4}{|l|}{ Household Size } \\
\hline Less than 6 & 1 & & \\
\hline
\end{tabular}

bold $=$ Significant at $p$-value $<0.05$, Final model - Adjusted for residence, region, working status, education level and wealth index. Sensitivity model - Included only women with low and normal BMI and excluded women with BMI equal to and above 25.0. AOR: Adjusted odds ratio. COR: Crude Odds Ratio 


\begin{tabular}{|c|c|c|c|}
\hline \multirow[t]{2}{*}{ Characteristics } & $\begin{array}{l}\text { Crude model }(n= \\
1356)\end{array}$ & $\begin{array}{l}\text { Final Model }(n= \\
1356)\end{array}$ & $\begin{array}{l}\text { Sensitivity Model }(n= \\
\text { 1067) }\end{array}$ \\
\hline & OR $(95 \% \mathrm{Cl})$ & AOR $(95 \% \mathrm{Cl})$ & AOR $(95 \% \mathrm{Cl})$ \\
\hline Six and above & \multicolumn{3}{|l|}{$1.89(0.60-1.32)$} \\
\hline \multicolumn{4}{|l|}{ Wealth Index } \\
\hline Richest & 1 & 1 & 1 \\
\hline Richer & $3.14(0.89-11.08)$ & $1.77(0.43-7.39)$ & $1.05(0.27-4.11)$ \\
\hline Middle & $2.60(0.74-9.14)$ & $1.27(0.31-5.12)$ & $0.74(0.20-2.69)$ \\
\hline Poorer & $4.48(1.35-14.89)$ & $1.74(0.42-7.15)$ & $0.91(0.25-3.28)$ \\
\hline Poorest & $8.02(2.49-25.86)$ & $1.79(0.45-7.05)$ & $0.92(0.26-3.25)$ \\
\hline \multicolumn{4}{|l|}{ Residence } \\
\hline Urban & 1 & 1 & \\
\hline Rural & $1.76(0.91-3.41)$ & $0.87(0.39-1.91)$ & \\
\hline \multicolumn{4}{|l|}{$\begin{array}{l}\text { Sex of household } \\
\text { head }\end{array}$} \\
\hline Male & \multicolumn{3}{|l|}{1} \\
\hline Female & \multicolumn{3}{|l|}{$1.08(0.70-1.68)$} \\
\hline \multicolumn{4}{|l|}{ ANC Frequency } \\
\hline 4 visits and above & \multicolumn{3}{|l|}{1} \\
\hline Less than 4 visits & \multicolumn{3}{|l|}{$1.13(0.72-1.77)$} \\
\hline \multicolumn{4}{|c|}{$\begin{array}{l}\text { bold = Significant at } p \text {-value }<0.05 \text {, Final model }- \text { Adjusted for residence, region, working status, } \\
\text { education level and wealth index. Sensitivity model }- \text { Included only women with low and normal BMI } \\
\text { and excluded women with BMI equal to and above } 25.0 \text {. AOR: Adjusted odds ratio. COR: Crude Odds } \\
\text { Ratio }\end{array}$} \\
\hline
\end{tabular}

\section{Sensitivity Analysis}

Analysis after excluding obese and overweight women and considering only women with a $\mathrm{BMI}<25$.

We conducted a sensitivity analysis where we excluded women who had a BMI equal to and above 25.0 and we coded underweight $(\mathrm{BMI}<18.5)$ as one and normal BMI $(18.5-24.9)$ coded as zero. The final adjusted model had no significant differences between the factors associated with underweight compared to the original analysis (Table 3). Education level, working status and region were still significantly associated with underweight. 


\section{Discussion}

This study investigated the prevalence and factors associated with underweight among lactating Ugandan women aged between 20 to 49 years. Based on the anthropometric measurement of body mass index, $8.2 \%$ (95\% Cl: 7.0-10.0), of lactating women were underweight with BMI less than $18.5 \mathrm{~kg} / \mathrm{m}^{2}$ which prevalence is below the standard acceptable malnutrition rate of $10 \%(23)$.Of the $8.2 \%, 3.6 \%$ were severely underweight, $20.5 \%$ were moderately underweight and $75.9 \%$ mildly underweight. This prevalence is lower than studies conducted among lactating women in Ethiopia $(5,8,12)$, rural Vietnam (24) and India (25) but higher than a study done in Nigeria (9). The difference in the prevalence of underweight between the current study and the other studies above could be attributed to the differences in the sociodemographic and economic characteristics between these study areas.

Underweight was significantly associated with working status, education level and region.

Women who belonged to the Western, Eastern and Central regions were less likely to be underweight compared to women in the Northern region. Region of residence has also been shown to be associated with undernutrition in similar low-income African settings $(4,26,27)$ and in Afghanistan (28). Some parts of Northern Uganda especially the North-Eastern area are among the most food insecure with limited resources $(29,30)$. This could be attributed to the fact that this region experienced a long civil war which greatly affected their agricultural production and the economy compared to the other regions of the country that have been stable without civil conflicts (31). The decreased agricultural production and poor economy of this region induced food insecurity by reducing local food production hence decreased availability and access to food. (32). This leads to inadequate food, in both quality and quantity, risking them to underweight. Additionally, most people in the Northern region, unlike the other regions are pastoral communities (some are nomadic) and this may negatively affect their consumption of foods from the agricultural origin (crops) as they mostly focus on pastoral activities. As a matter of fact, pastoralism has been shown to increase the risk of underweight in Ethiopian pastoral communities (4).

Women who were not working were $49 \%$ less likely to be underweight compared to those who were working. Working status has been shown in other studies conducted in Ethiopia, Senegal and Cambodia to be associated with underweight $(12,33,34)$. The workload due to labour- intensive activities that involve high physical activity increase energy expenditure which further predisposes these women to underweight. Similarly, a study done among lactating Senegalese women shows weight loss due to negative energy balance associated with agricultural labour (33) which agricultural activities are the commonest source of income in Uganda (18). Another possible reason could be tight working schedules affect the dietary patterns of lactating mothers, this, coupled with the increased nutrition needs, makes lactating mothers prone to underweight $(35,36)$.

Similar to studies done in Ethiopia (12), Nepal (2), Tanzania (4), Iran (1), Kenya (37) and Botswana (38), education level in this study was significantly associated with the nutritional status. Women who had no education and those with primary level were 9.27 and 6 times more likely respectively, to be underweight

Page $13 / 20$ 
compared to those that had a post-secondary level of education. Education level has been shown to be one of the indicators of women empowerment hence less educated women tend to have less nutrition knowledge, be less empowered to access economic resources and also less likely to make right decisions (2) which negatively affects the use of health-care facilities, accessibility of nutritious food, better healthpromoting behaviours and management of the limited household resources. All these predisposes them to inadequate dietary intake due to poor dietary consumption patterns like skipping meals and /or having unbalanced diets and eventually leading to underweight (39).

\section{Strengths}

Standardised procedures are a requirement of DHS surveys in data collection and validated questionnaires were used which ensured the internal and external validity of the results.

Secondly, we used a nationally representative sample and weighed the data for analysis and therefore our results are generalized to all Ugandan women aged 20 to 49 years.

\section{Limitations}

The cross-sectional design is limited by lack of temporality hence causality inferences cannot be made. Most data on the predictors was based on self-reporting and could not be verified through records which risks socially acceptable answers hence information bias. Other important predictors of underweight such as dietary diversity score, nutritional knowledge, co-morbidities and food security were not available to be included in the analysis. There is also possibility of recall and interviewer biases as respondents gave answers about events that occurred in the past and possibility of respondents giving positive answers to please the interviewer.

\section{Conclusion}

Based on the anthropometric measurement of body mass index, $8.2 \%(95 \% \mathrm{Cl}: 7.0-10.0)$, of lactating women were underweight with BMI less than $18.5 \mathrm{~kg} / \mathrm{m}^{2}$ which prevalence is below the standard acceptable malnutrition rate of $10 \%$ (23). Our study established that the factors associated with underweight among Ugandan lactating women were level of education, working status and region. Based on the findings of this and other studies, it is important for the government to design targeted underweight reduction programs with special emphasis on working, women from the Northern region and those whose highest level of education is primary.

\section{Abbreviations}

EA Enumeration area 
AOR Adjusted Odds Ratio

Cl Confidence Interval

COR Crude Odds Ratio

DHS Demographic Health Survey

UDHS Uganda Demographic Health Survey

OR Odds Ratio

SD Standard Deviation

WHO World Health Organization

BMI Body Mass Index

GDP Gross Domestic Product

SPSS Statistical Package for Social Science

USAID United States Agency for International Development.

Kg Kilograms

UNICEF United Nations Children's Fund

ANC Antenatal Care

\section{Declarations}

\section{Availability of data and materials}

The data set used is openly available from MEASURE DHS website and the modified data set that was used for final analysis can be availed upon request from the corresponding author.

\section{Ethics approval and consent to participate}

High international ethical standards are ensured for MEASURE DHS surveys as ethical approval from the country is obtained from a national ethical review board and local authorities before implementing the survey and well-informed verbal consent is sought from the respondents prior to data collection $(16,20)$ This data set was obtained from the MEASURE DHS website (URL: 
https://www.dhsprogram.com/data/available-datasets.cfm) after getting their permission and no formal ethical clearance was obtained since we conducted secondary analysis of publicly available data.

\section{Consent for publication}

Not applicable.

\section{Competing interests}

All authors declare that they have no competing interests.

\section{Funding}

No funding was obtained for this study.

\section{Authors' contributions}

QS Conceived the idea, drafted the manuscript, performed analysis and interpreted the results. DM participated in conceiving the idea and helped in results interpretation and writing. JK, MM. MK, IAK, HT, LMM and RT reviewed the first draft and drafted the subsequent versions of the manuscript. All authors read and approved the final manuscript.

\section{Acknowledgements}

We thank the MEASURE DHS program for availing us with the data.

\section{Author details}

${ }^{1}$ QS is currently a monitoring and evaluation manager at Doctors with Africa, Juba, South Sudan.

${ }^{2} \mathrm{DM}$ has recently completed his PhD at the Centre for International Health, University of Bergen, Norway and is currently working at Sanyu Africa Research Institute, Mbale, Uganda and Makerere University College of Health Sciences.

${ }^{3}$ LMM is a former global health masters' student at Uppsala University, Sweden

${ }^{4} \mathrm{MM}$ is the Head of Department of Obstetrics and Gynaecology, Mbale Regional Referral Hospital and a PhD student at Makerere University College of Health Sciences, Uganda.

${ }^{5} \mathrm{MK}$ is a master's student at the department of Obstetrics and Gynaecology, Makerere University College of Health Sciences, Uganda 
${ }^{6}$ IAK is a working at the school of public health, Makerere University College of Health Sciences, Uganda

${ }^{7} \mathrm{RT}$ is a research assistant in the department of Psychiatry, Michigan State University, USA

${ }^{8} \mathrm{TH}$ is currently pursuing his $\mathrm{PhD}$ at the Centre for International Health, University of Bergen, Norway.

${ }^{9} \mathrm{JK}$ is currently finishing his master's degree at Global Health School of Public Health, Southeast University, Nanjing, 210009, Jiangsu Province, China.

\section{References}

1. Mardani M, Abbasnezhad A, Ebrahimzadeh F, Roosta S, Rezapour M, Choghakhori R. Assessment of Nutritional Status and Related Factors of Lactating Women in the Urban and Rural Areas of Southwestern Iran: A Population-Based Cross-Sectional Study. International journal of community based nursing midwifery. 2020;8(1):73-83.

2. Kshatriya GK, Acharya SK. Gender Disparities in the Prevalence of Undernutrition and the Higher Risk among the Young Women of Indian Tribes. PLoS One. 2016;11(7):e0158308-e.

3. Vir SC. Improving women's nutrition imperative for rapid reduction of childhood stunting in South Asia: coupling of nutrition specific interventions with nutrition sensitive measures essential. Maternal Child Nutrition. 2016;12(S1):72-90.

4. Mtumwa AH, Paul E, Vuai SAH. Determinants of undernutrition among women of reproductive age in Tanzania mainland. South African Journal of Clinical Nutrition. 2016;29(2):75-81.

5. Desalegn BB, Lambert C, Riedel S, Negese T, Biesalski HK. Ethiopian Orthodox Fasting and Lactating Mothers: Longitudinal Study on Dietary Pattern and Nutritional Status in Rural Tigray, Ethiopia. International journal of environmental research and public health. 2018;15(8).

6. Singh DR, Ghimire S, Upadhayay SR, Singh S, Ghimire U. Food insecurity and dietary diversity among lactating mothers in the urban municipality in the mountains of Nepal. 2020;15(1):e0227873.

7. Aleni M, Mbalinda SN, Muhindo R. Birth Intervals and Associated Factors among Women Attending Young Child Clinic in Yumbe Hospital, Uganda. 2020;2020:1326596.

8. Haileslassie K, Mulugeta A, Girma M. Feeding practices, nutritional status and associated factors of lactating women in Samre Woreda, South Eastern Zone of Tigray, Ethiopia. Nutrition journal. 2013;12:28.

9. Ukegbu P, Ogechi. A Study of the Nutritional Status and Dietary Intake of Lactating Women in Umuahia, Nigeria. American Journal of Health Research. 2014;2(1):20-6. doi:10.11648/j.ajhr.20140201.14.

10. Hundera TD, Wirtu D, Gemede HF, Kenie DN. Nutritional Status and Associated Factors Among Lactating Mothers in Nekemte Referral Hospital and Health Centers, Ethiopia. International Journal of Nutrition Food Sciences. 2015;4(2):216-22. doi:10.11648/j.ijnfs.20150402.23. 
11. Berihun S, Kassa GM, Teshome M. Factors associated with underweight among lactating women in Womberma woreda, Northwest Ethiopia; a cross-sectional study. BMC Nutrition. 2017;3(1):46.

12. Tikuye HH, Gebremedhin S, Mesfin A, Whiting S. Prevalence and Factors Associated with Undernutrition among Exclusively Breastfeeding Women in Arba Minch Zuria District, Southern Ethiopia: A Cross-sectional Community-Based Study. Ethiopian journal of health sciences. 2019;29(1):913-22.

13. Gebre B, Biadgilign S, Taddese Z, Legesse T, Letebo M. Determinants of malnutrition among pregnant and lactating women under humanitarian setting in Ethiopia. BMC Nutrition. 2018;4(1):11.

14. Hailu, Bekele. Gebi Husein Jima,Ashenafi Habtamu Regesu: Undernutrition and Associated Factors among Lactating Women: Community-Based Cross-Sectional Study in Moyale District, Borena Zone, Southern Ethiopia, Advances in Public Health, Volume 2020 |Article ID 4367145 | 10 pages | https://doi.org/10.1155/2020/4367145.

15. Okot-Okumu J, Oosterveer P. Providing Sanitation for the Urban Poor in Uganda. In: van Vliet B, Spaargaren G, Oosterveer P, editors. Social Perspectives on the Sanitation Challenge. Dordrecht: Springer Netherlands; 2010. pp. 49-66.

16. Uganda Bureau of Statistics - UBOS, ICF. Uganda Demographic and Health Survey 2016. Kampala: UBOS and ICF; 2018.

17. Turcan,Lilia and Bene,Tim. A review of policies for improving human nutrition in Uganda and the use of evidence for making policy. Montpellier, France: Agropolis International, Global Support Facility for the National Information Platforms for Nutrition initiative. 2017.http://www.nipn-nutritionplatforms.org/IMG/pdf/nutrition-policy-making-uganda.pdf.

18. Central Intelligence Agency. The World Fact Book: Uganda January 2019 www.cia.gov/library/publications/the-world-factbook/geos/ug.

19. Benova L, Dennis ML, Lange IL, Campbell OMR, Waiswa P, Haemmerli M, et al. Two decades of antenatal and delivery care in Uganda: a cross-sectional study using Demographic and Health Surveys. BMC Health Serv Res. 2018;18(1):758-.

20. Rutstein SO, Staveteig S. Making the Demographic and Health Surveys Wealth Index comparable. Maryland: ICF International: Rockville; 2014.

21. Yang YY, Kaddu G, Ngendahimana D, Barkoukis H, Freedman D, Lubaale YA, et al. Trends and determinants of stunting among under-5s: evidence from the 1995, 2001, 2006 and 2011 Uganda Demographic and Health Surveys. Public Health Nutr. 2018;21(16):2915-28.

22. Lee PH, Burstyn I. Identification of confounder in epidemiologic data contaminated by measurement error in covariates. BMC medical research methodology. 2016;16:54-.

23. Desyibelew HD, Dadi AF. Burden and determinants of malnutrition among pregnant women in Africa: A systematic review and meta-analysis. PLoS One. 2019;14(9):e0221712.

24. Nakamori $M$, et al. Nutritional status of lactating mothers and their breast milk concentration of iron, zinc and copper in rural Vietnam. J Nutr Sci Vitaminol (Tokyo). 2009;55(4):338-45. 
25. Khan YM, Khan A. A study on factors influencing the nutritional status of lactating women in Jammu, Kashmir and Ladakh regions. Inter J Advancements Res Technol. 2012;1(4):65-74.

26. Senbanjo IO, Olayiwola IO, Afolabi WA, Senbanjo OC. Maternal and child under-nutrition in rural and urban communities of Lagos state, Nigeria: the relationship and risk factors. BMC Res Notes. 2013;6:286-.

27. Kenya National Bureau of Statistics, Ministry of Health/Kenya, National AIDS Control Council/Kenya. Kenya Medical Research Institute, Population NCf, Development/Kenya. Kenya Demographic and Health Survey 2014. Rockville, MD, USA: 2015.

28. Akseer N, Bhatti Z, Mashal T, Soofi S, Moineddin R, Black RE, et al. Geospatial inequalities and determinants of nutritional status among women and children in Afghanistan: an observational study. The Lancet Global Health. 2018;6(4):e447-e59.

29. Wichern J, van Wijk MT, Descheemaeker K, Frelat R, van Asten PJA, Giller KE. Food availability and livelihood strategies among rural households across Uganda. Food Security. 2017;9(6):1385-403.

30. USAID. Food Assistance Fact Sheet Uganda. Updated February 18, 2020. file:///C:/Users/hp/Downloads/FFP_Uganda_Fact_Sheet.pdf.

31. Girma W and Timotiows Genebo... ., : Macro ORC. Determinants of Nutritional Status of Women and Children in Ethiopia. Maryland: Calverton; 2002. https://dhsprogram.com/pubs/pdf/FA39/02nutrition.pdf.

32. Tusiime HA, Renard R, Smets L. Food aid and household food security in a conflict situation: Empirical evidence from Northern Uganda. Food Policy. 2013;43:14-22.

33. Simondon KB, Ndiaye T, Dia M, Yam A, Ndiaye M, Marra A, Diallo A, Simondo F. Seasonal variations and trends in weight and arm circumference of nonpregnant rural Senegalese women, 1990-1997. Eur J Clin Nutr. 2008;62:997-1004.

34. Wang Z, Dang S, Xing Y, Li Q, Yan H. Dietary patterns and their associations with energy, nutrient intake and socioeconomic factors in rural lactating mothers in Tibet. Asia Pac J Clin Nutr. 2017;26(3):450-6.

35. Johnston ML, Esposito N. Barriers and facilitators for breastfeeding among working women in the United States. Journal of obstetric gynecologic neonatal nursing: JOGNN. 2007;36(1):9-20.

36. Guendelman S, Kosa JL, Pearl M, Graham S, Goodman J, Kharrazi M. Juggling work and breastfeeding: effects of maternity leave and occupational characteristics. Pediatrics. 2009;123(1):e38-46.

37. Masibo PK, Buluku E, Menya D. VC Malit; Prevalence and determinants of under-and over-nutrition among adult Kenyan women; evidence from the Kenya demographic and health survey 2008-09; East African Journal of Public Health; Vol 11, No 1 (2014).

38. Letamo G, Navaneetham K. Prevalence and determinants of adult under-nutrition in Botswana. PLoS One. 2014;9(7):e102675-e.

39. Haseen F. Malnutrition among ultra poor women in Bangladesh: Malnutrition among Bangladeshi Women in Ultra Poor Households: Prevalence and Determinants. Germany: LAP Lambert Academic 
Publishing; 2010. 52 p. 